\title{
A Peritoneal Sac Enclosing the Small Intestine ${ }^{122}$
}

\author{
By \\ Hiroshi Hosokawa and Yasuko Nakajima \\ Department of Anatomy, University of Tokyo \\ Faculty of Medicine, Hongo, Tokyo
}

Apart from the extensive adhesions and thickenings of the peritoneum due to inflammatory diseases, there have been reported a considerable number of peritoneal anomalies which were represented by a sac enclosing a part or the whole of the small intestine.

They were often called "peritonitis chronica fibrosa incapsulata", because some authors regarded them as remnants of the chronic inflammatory processes of the peritoneum. Some others, however, regarded them as congenital peritoneal anomalies, since they could find no sign of the inflammatory changes such as adhesions, thickenings, fluid, etc.

Most of these reported cases were observed in the surgical operation room, because these anomalies often gave occasion to the ileus of different grades. This situation explains why the authors could give only brief anatomical descriptions of these malformations.

The present writers were encountered with a peritoneal sac of a similar sort in a human cadaver which was dissected in the gross anatomy laboratory for the medical freshmen. So they could examine carefully and precisely the anatomical details of this specimen which showed some peculiarities different from previous reports.

The cadaver (No. 2153) was a man, 75 years of age, who had died on Jan. 9, 1960, because of the heart insufficiency. Some anatomical data of this cadaver are as follows: Body length $152 \mathrm{~cm}$; body weight $40.5 \mathrm{~kg}$; brain $1320 \mathrm{~g}$; heart $420 \mathrm{~g}$ (without blood $340 \mathrm{~g}$ ) ; lung: right $1400 \mathrm{~g}$, left $1000 \mathrm{~g}$; liver ?; pancreas $50 \mathrm{~g}$; spleen $51 \mathrm{~g}$; kidney : right $135 \mathrm{~g}$, left $120 \mathrm{~g}$; length of small intestine $694 \mathrm{~cm}$; length of large intestine $125 \mathrm{~cm}$.

1) Dedicated to Prof. Dr. T. Og a w a for his Sixtieth Birthday.

2) This paper was read in the 22nd Anatomical Meeting of Kanto-District, May 13, 1961. 


\section{Observations}

When the abdominal wall was cut open along the mid-ventral line, a large, somewhat oval sac with thin membranous wall was found to occupy almost the whole abdominal cavity. The wall was smooth, even and showed no sign of perforations, callous thickenings

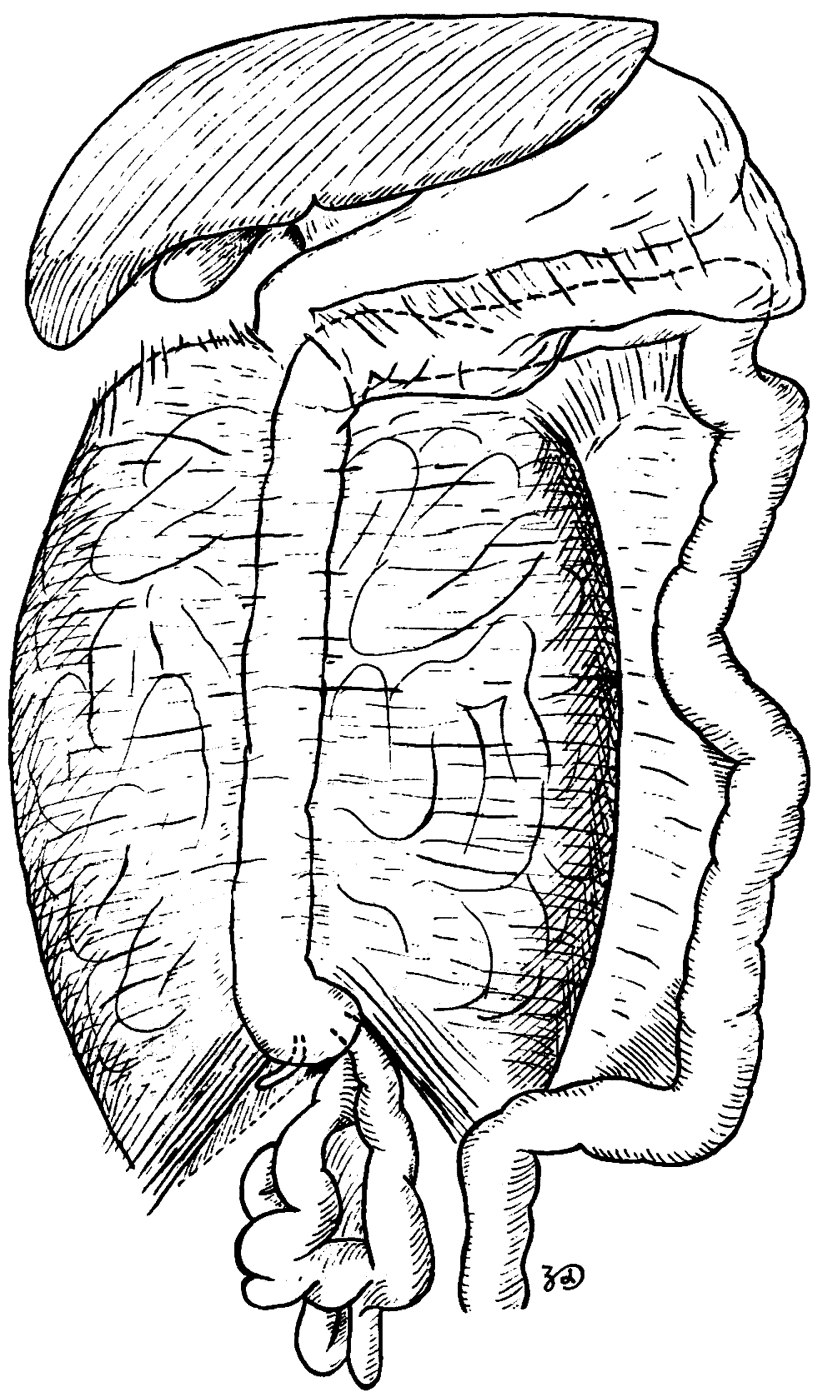

Fig. 1. Anterior view of the peritoneal sac. The ascending colon is involved in the anterior wall of the sac. 
or adhesions. It was fairly thin and the winding of intestine was vaguously seen inside the sac (figs. 1, 7).

Different from all the reported cases excepting that of $\mathrm{H}$ a $\mathrm{s} \mathrm{u}-$ $\mathrm{n} u \mathrm{ma}$ ('54), the ascending colon is suspended and enclosed in the membranous wall at about the mid-ventral line of the sac, dividing the latter into the right and left halves. The right half or lobe of the wall extends from the right margin of the ascending colon towards the right lateral wall of the abdominal cavity so as to continue with the partietal peritoneal lining, while the left half or lobe extends left-wards and, after surrounding loops of the small intestine, adheres to the peritoneal wall nearly at the middorsal line along the anterior surface of the vertebral column (figs. $2,3,8)$.

The superior end of the sac is bordered by the liver and stomach. After making a slight, temporary adhesion to the under surface of
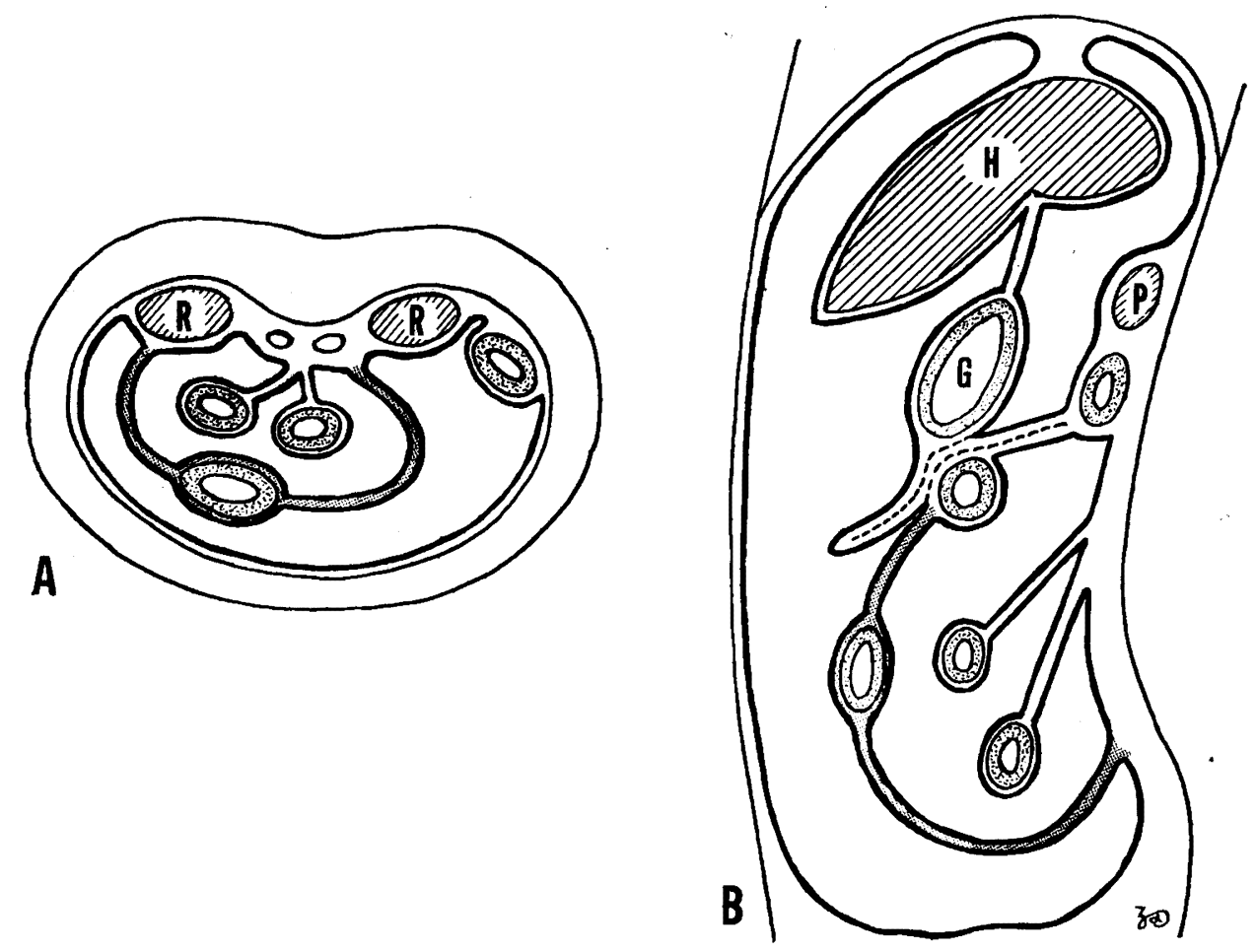

Fig. 2. Diagrammatic illustration of the peritoneal sac.

A : transverse section. B : median sagittal section.

H-liver, G-stomach, P-pancreas, R-kidney. 


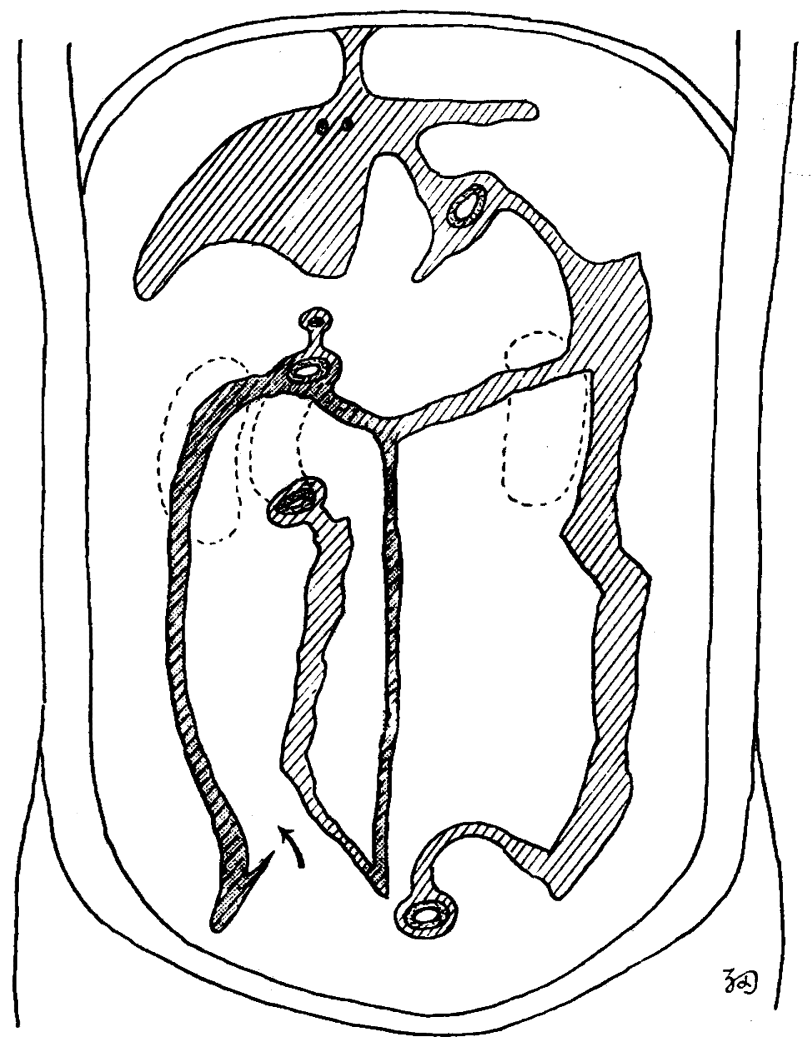

Fig. 3. Attachment of the peritoneal sac to the posterior abdominal wall. The arrow shows the site of passage into the sac.

liver and gall-bladder, the superior end of the right lobe turns backwards and continues to the dorsal wall of the abdominal cavity. The transverse colon and its mesentery, mescolon transversum, abut on the left half of the sac. At this place the sac makes contact with the mesocolon and, so to say, continues to the latter, although the mesocolon gives a little looser appearance than the membranous wall of the sac. The greater omentum is evidently present, showing normal relationship to the transverse colon as well as to the greater curvature of the stomach (figs. 7, 8). The omentum itself is, however, reduced in size, extending only about fifteen $\mathrm{cm}$. downwards.

At the inferior end of the sac there is a foramen which represents the only passage from inside of the sac, and a loop of 
small intestine was seen to come out through this foramen so as to. descend into the pelvic cavity (figs. 13, 14). This foramen is located just under the caecum and its lateral borders are formed by two ligamentous plicae which, arising from the lateral surfaces of the caecum, diverge obliquely laterocaudad. The right plica runs along the right external iliac artery and adheres to the medial surface of the psoas muscle, while the left one extends into the pelvic cavity towards the sigmoid colon.

When the sac is cut open, the winding of the small intestine comes into sight (figs. 9, 10). It was furnished with well developed mesentery, of which the root, radix mesenterii, runs longitudinally on the anterior surface of the vertebral column, slightly deviated to the right of the median plane. As shown in fig. 3, the inferior end of the radix mesenterii turns upward to continue to the attachment line of the left lobe of the sac. The above mentioned loop of intestine descending into the pelvic cavity drags long mesentery with it. The windings of the small intestine showed no adhesions among them.

The internal surface of the sac is everywhere as smooth as the external (figs. 11, 12). On the back surface of the caecum the apex of the vermiform appendix is seen projecting several $\mathrm{cm}$ (fig. 14). Besides, two slight plicae are seen, each on one side, to run craniolaterad so as to suspend the caecum.

As shown in figs. 1 and 3, the transverse, descending and sigmoid colons as well as the rectum are outside the sac and are disposed rather normally.

\section{Arterial supply of the intestines}

The arteries to the small and large intestines were examined and it was revealed that the general principal of the distribution pattern was almost the same as in normal cases. As shown in fig. 4, the superior mesenteric artery supplies the whole windings of small intestine as well as the ascending and transverse colon, while the descending and sigmoid portions of the colon as well as the greater part of the rectum receive branches from the inferior mesenteric artery.

It should be noted that the ascending colon enclosed in the wall of the sac receives branches from the a. colica media above and from the a. ileocolica below. These branches run through the superior and inferior portions of the left lobe of the sac and, after 


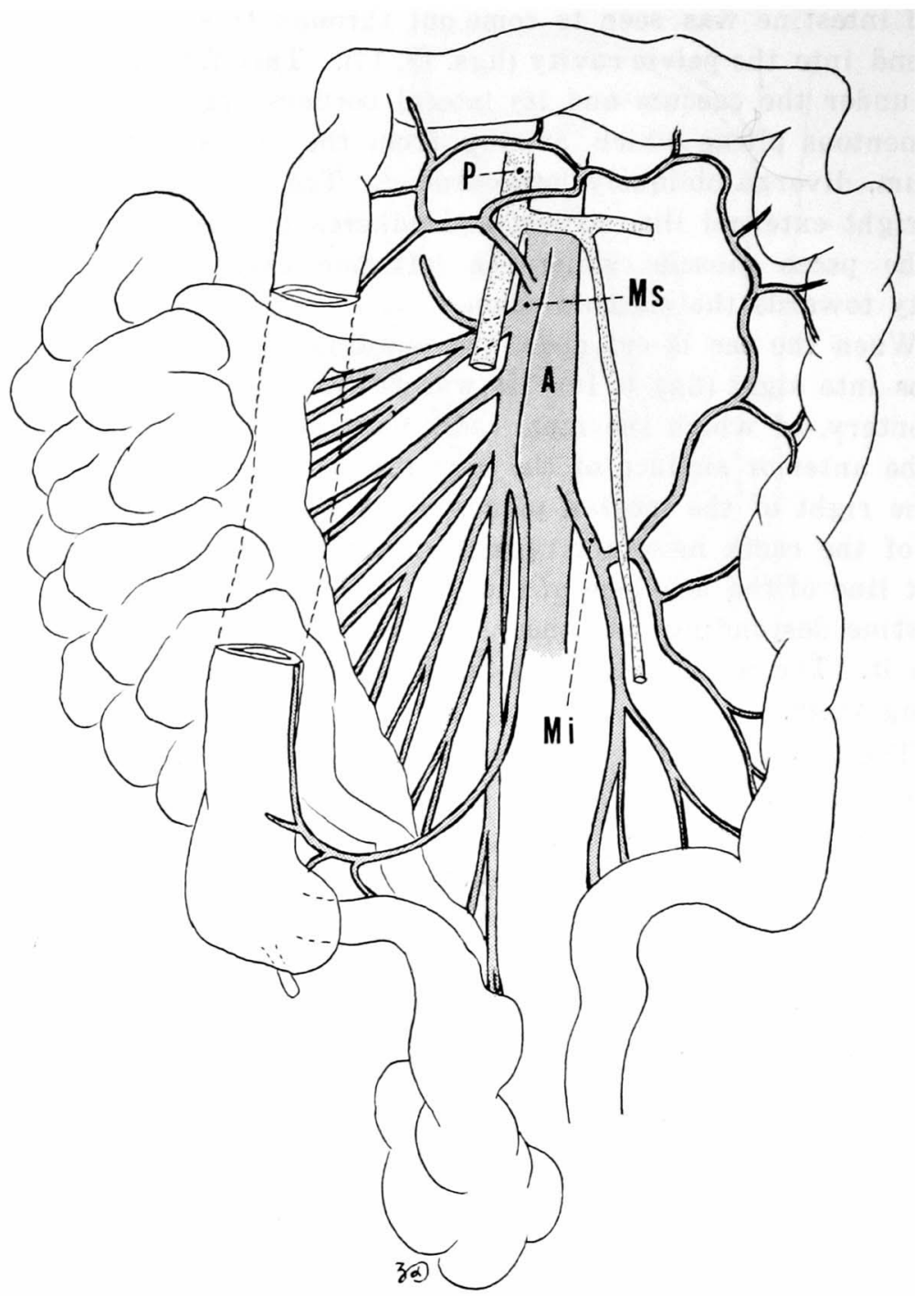

Fig. 4. Arterial supply to the small and large intestines. A-abdominal aorta, Mi-inferior mesenteric artery, Ms-superior mesenteric artery, P-portal vein.

arriving at the colon, follows the latter along its left border. The walls of the sac are poorly supplied with blood vessels. although the regions adjacent to the ascending colon are fairly well vascularized histologically. 
Microsocopic structure of the sac

The membranous wall of the sac is composed mainly of collagen fibers arranged in irregular networks. The outer and inner surfaces are smooth and show no sign of mesothelial lining, which may have been rubbed off. Cell elements are rather scanty in the stroma and the fat tissue is poorly developed. Blood vessels are also scarcely distributed, while the areas adjacent to the ascending colon is, especially on the left lobe, fairly well vascularized.

\section{Discussion}

As already mentioned, some authors who found saccular anomalies of the peritoneum thought that these anomalies were caused by the chronic inflammatory processes such as tuberculosis, appendicitis, cholecystitis, etc. (T i e s e n ha u e n, '25; A b r m ow its ch, '26; S hiod a, '27; Schrödl, '27; J o s a, '27; T o ol e, '29; S c hubin, '29; B orkowski, '30; Jungling, '30; Soekar jo, ' 31 ; Hochmiller, '31; Nakata, '31; I wamoto, '33; Ozawa \& Shimada, '57; Takahashi \& Uno, '58).

In the matter of fact there have been many cases where the peritoneum showed evidently pathological adhesions, callous thickenings, tubercles, fluid, etc. and this is why these cases were often called "peritonitis chronica fibrosa incapsulata s. incapsulans" or the "sugar poured intestine" ( $\mathrm{Z} \mathrm{u} \mathrm{c} \mathrm{k} \mathrm{e} \mathrm{r} \mathrm{g} \mathrm{u} \mathrm{s} \mathrm{s} \mathrm{d} \mathrm{a} \mathrm{m).} \mathrm{They} \mathrm{were}$ also called with various names such as "péritonite rétractile et néomembraneuse" ( $\mathrm{A} \mathrm{badi}$ ), "mésentérite cicatricelle", "peritonitis chronica saccata", "peritonitis chronica adhaesive indiopathica" (Borkowski), "serositis chron. adhaesiva jejuni-ilei" ( $\mathrm{T}$ i e se $\mathrm{nh}$ a u se n), etc. In many cases the intestinal loops inside the sac were adhered to each other and, together with the callous sac, formed a conglomerate.

But the authors could not explain the formation of the sac itself through the pathological changes of the peritoneum. For nobody could ascertain the transition from the inflammatory fibroplastic pseudomembranes to the peritoneal membranous sac. Furthermore, there were many cases where the sac was too regularly and neatly formed to be regarded as pathological, inflammatory product, convincing some authors that the sacs are congenital anomalies. (Lickery \& Cameron, '06; Ikegami, '08; A badie, '22; Lübke, '22; Murat, '22;R eid, '25; Gond o, '26; Moskalen- 
kow, '26; Füth, '27; Lorin-Epstein, '32; R ubasev, '35; Y a m a moto, '39; K a n ad a, '41; W a k a n a, '41; $\mathrm{N}$ is hi y a ma, '52; H a s u u ma, '54; F u k u d a, '54.)

Thus Jüngling ('30), Lorin-Epstein ('32) and others were lead to the conclusion that the peritonitis chronica fibrosa incapsulata is not represented by a single disease but comprises compound processes or factors such as embryological anomaly, hernia, fibroplastic disposition, inflammatory disease, etc.

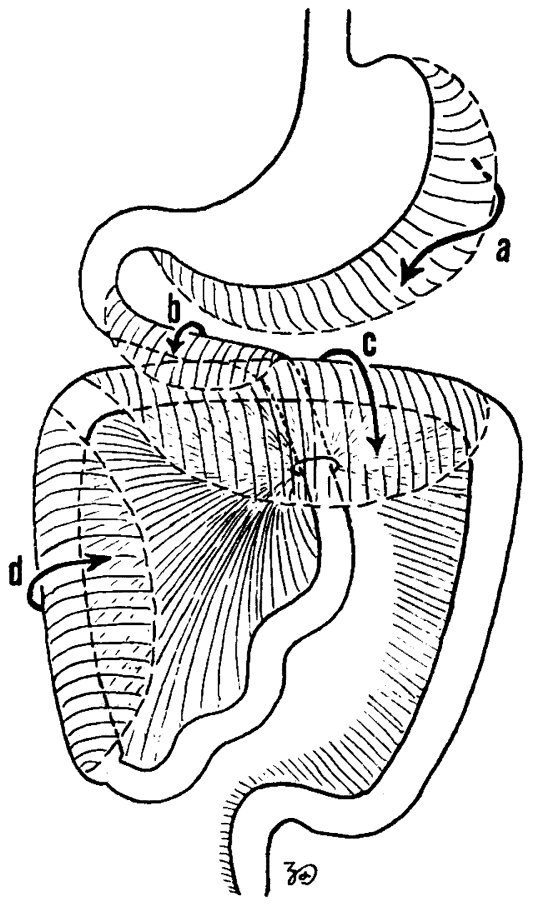

Fig. 5. Possible origins of the peritoneal sac for enclosing the small intestine.

a-from omentum majus, b-from mesoduodenum, c-from mesocolon transversum, d-from mesocolon ascendens.

Accepting that some congenital disorder participates in the formation of the peritoneal sac in question, it is still not easy to get a reasonable developmental anatomical interpretation of such a peculiar sac. According to L ü b k e ('22), Dr. W a l d e y e r, the famous German anatomist, could not give an adequate embryological explanation of an anomalous peritoneal plate covering the ileo-caecal region.

As shown in fig. 5, several possibilities are thinkable about the origin and development of the peritoneal sac.

(1) The easiest and most plausible way is to seek the origin of the sac in the greater omentum which may develop so extra-ordinarily that it encloses the windings of small intestine and adheres to the posterior abdominal wall. Other sourses are represented by the (2) mesoduodenum, (3) mesocolon transversum, and (4) mesocolon ascendens. Although these mesenteries do not show usually omentum-like extensions, it may happen just as the dorsal mesogastrium gives rise to the greater omentum.

(5) The ventral mesentery may represent another possible origin of such an anomalous sac, if it happens to be preserved in 
the caudal portion of the alimentary tract.

Most of the peritoneal sacs reported previously, where the ascending colon had nothing to do with the sac and only the small intestine was wholly or partly enclosed in the sac, can be explained by one or two of these possibilities just mentioned. But the present case as well as that of $\mathrm{Has}$ a n $\mathrm{ma}$ ('54), where the ascending colon is involved in the ventral wall of the sac, can hardly be explained by any of them.

The first question to be answered is this: Which of the right and left lobe of the membranous sac is derived from the original mesocolon ascendens? Although the position of the attachment line to the posterior abdominal wall appears to favor the right lobe, the fact that the mesenteric root of small intestine is continuous with the attachment line of the left lobe, while it is interrupted by the foramen behind the caecum from that of the right lobe (fig. 3), as well as the fact that the arteries supplying the ascending colon pass through the superior and inferior portions of the left lobe (fig. 4), seems to indicate that the left lobe corresponds to the original mesocolon ascendens.

If the normal development of the intestinal loop and its anticlockwise rotation, which should take place at about the sixth or seventh fetal week, are slightly modified in such a way as illustrated diagrammatically in fig. 6 , probably due to the poor development of the retention bands, it is anyhow possible to explain the formation of the left lobe of the sac.

It should be noted that this possibility explains the formation of the anomalous sacs without involving the ascending colon, by supposing the adhesion of the ascending mesocolon to the posterior abdominal wall on the right side of the intestinal winding, more easily and clearly than any of the above mentioned five hypotheses.

The next question concerns the origin of the right lobe. The preserved ventral mesentery should be considered at first. But the fact that the right lobe does not show traces of the cranio-caudal torsion which should have taken place at the time of rotation of the intestinal loop, rather neglects this possibility.

So the only way seems to suppose an omentum-like extension of the mesocolon ascendens, which has formed the left lobe of the sac, towards the right side, as shown by dotted line in fig. 6-D. 


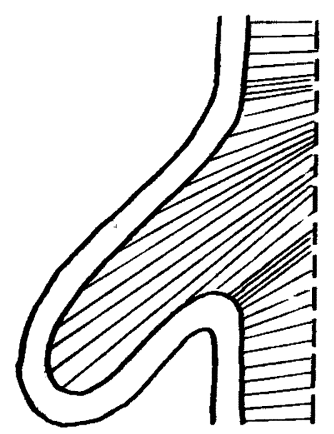

A

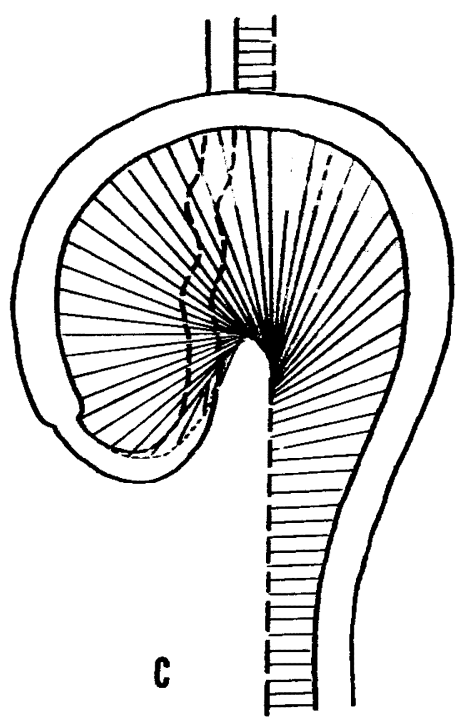

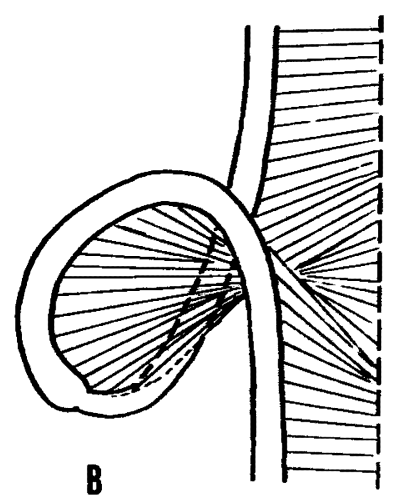

B

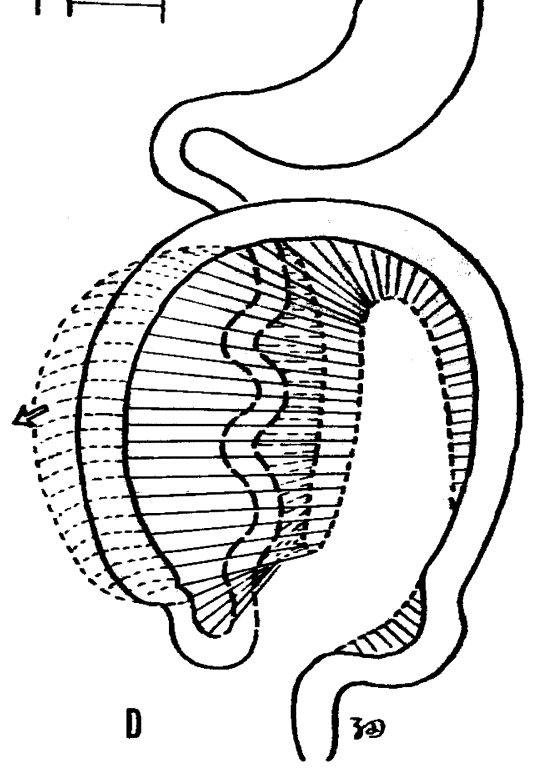

Fig. 6. A hypothetical explanation of the development of the peritoneal sac which encloses the?windings of the small intestine.

\section{Summary}

An anomalous peritoneal sac enclosing almost completely the windings of the small intestine was encountered in a human cadaver dissected in the gross-anatomy laboratory. Judging from the general features, it seems apparent that this peritoneal sac is not formed by pathological changes of the peritoneum such as inflammatory adhesions. Different from the cases reported hitherto, the present specimen shows a peculiarity that the ascending colon is involved 
in the anterior wall of the sac.

Topographical relations of the sac to the mesentery proper as well as the mode of arterial supply to the ascending colon suggests that the left half or lobe of the sac is derived from the original ascending mesocolon, while the right half may be formed by the omentum-like extension of the same mesocolon.

\section{Literature Cited}

1) A b a die, M.J. (1922). Deux cas de mésenterite sclérosante rétractile, l'une aquise l'autre apparement congenitale. Bulletins et Mémoires de la Societé nationale de Chirurgie, 1922, 807-810.

2) A bramowitsch, W. (1926). Ueber peritonitis chronica fibrosa incapsulata. Zentb. f. Chir., 1926, Nr. 25, S. 1585.

3) Borkow ski, I. (1930). Beitrag zur Peritonitis chron. adhaesiva idiopathica. Zentb. f. Chir., 1930, Nr. 5, 262-264.

4) F u k u a, H. (1954). Three cases of the peritonitis chronica fibrosa incapsulata. (in Japanese) Surgery, $16: 45-46$.

5) F ü t h, R. (1927). Die angeborene Einkapselung des Zuckergussdarmes. Münch. med. Woch. schr., $74: 319-322$.

6) Gondo, T. (1926). Ileus due to the peritoneal anomaly. (in Japanese) Jap. J. Surg., 27 : 1767-1775.

7) H a s u n ma, T. (1954). A case of peritonitis chron. fibrosa incapsulata complicated by the common mesentery. (in Japanese) Clinical diseases of digestive organs, 2 : 395-398.

8) Hochmiller, R. (1931). Ueber zwei Fälle von Peritonitis chronica fibrosa incapsulans (Zuckergussdarm). Zentb. f. Chir., 1931, Nr. 51, 3204-3209.

9) I kegami, K. (1908). A rare case of the peritoneal anomaly. (in Japanese) Kenyokai Zassi, $87: 39-48$.

10) I w a mot o, M. (1933). Peritonitis chronica fibrosa incapsulata. (in Japanese) Naigai Chiryo, 8 : 783-791.

11) J o s a, L. (1927). Ueber Peritonitis chronica incapsulans (Zuckergussdarm). Zentb. f. Chir., 1927, Nr. 27, S. 1689.

12) J ü n g li n g, O. (1930). Ueber fibrös-plastische Veränderungen des Peritoneums. Deut. Z. f. Chir., $227: 284-296$.

13) K a nada, K. (1941). The cases of the peritonitis chronica fibrosa incapsulata. (in Japanesa) Osaka Iji-shinshi, 12 : 1034-1049.

14) L i ckley, J.D. and J. Cameron (1906). Note on a case of abnormal disposition of the peritoneum. J. Anat. Physiol., $41: 1$.

15) Lorin-Epstein, M. J. (1932). Hernia membrano-omentalis (Jejuno-ilei). Beitrag zur Lehre der inneren abdominalen Brüche nebst Bemerkungen über die Peritonitis fibrosa chronica incapsulata. Arch. f. klin. Chir., $17: 744-757$.

16) L ü b ke, (1922). Ein seltener Fall von Ileus. Deut. med. Woch. schr., 48 : 905.

17) Moska lenkow, A.N. (1926). Zentralorgan f. d. ges. Chir. u. ihre Grenzgebiete, 35 : 562 . (Cited from L ä w e n, A., 1937, Ueber chronish-fibröse inkapsuliererde Peritonitis. B r u n's Beitr., 166 : 635-646.)

18) Murat. A.W. (1922). An unusual case of intestinal obstruction. Arch. of 
Surg., $4: 690-692$.

19) N a k a ta, M. (1931). A supplement on the peritonitis chronica fibrosa incapsulata. (in Japanese) Grenzgebiet, $5: 331-340$.

20) N i shi y a ma, M. (1952). A case of peritonitis chron. fibrosa incapsulata. (in Japanese) Kagoshima Med. J., $25: 98$.

21) $\mathrm{Ozawa}, \mathrm{A}$. and K. Sh i mada (1957). Roentgenographic observation of a peritonitis chron. fibrosa incapsulata. (in Japanese) Clin. Roentgenology, 2: 475-479.

22) Reid, D. (1925). A peritoneal sac containing the small intestine. Zentorg. f. d. ges. Chir. u. ihre Grenzgebiete, 31 : 682. (Cited from L ä w e n, 1937, Ueber chronisch-fibröse inkapsulierende Peritonitis. Brun's Beitrag, 166 : 635-646.)

23) Rubasev, S. (1935). Zur Frage der chronischen abkapselnden Bauchfellentzündung. Zentorg. f. d. ges. Chir. u. ihre Grenzgeb., $74: 237-238$.

24) Schrö dl (1927). Ueber einen Fall von Zuckergussdarm. Zentb. f. Chir., 1927, Nr. 29, S. 1816. (Münch. med. Woch. schr., 1926, Nr. 36, S. 1482).

25) Schu bi n, W.N. (1929). Zur Frage der chronishen inkapsulierenden Peritonitis. Zentb. f. Chir., 1929, Nr. 22, S. 1388.

26) Shiota, H. (1927). Chronic intraabdominal diseases. (in Japanese) Grenzgebiet, 1, 1536-1553.

27) So e k a r jo (1931). Ein Fall von Peritonitis chronica fibrosa incapsulans (Zuckergussdarm). Zentb. f. Chir., 1931, Nr. 34, 2145-2146.

28) T a k a ha sh i, H. and $\mathrm{H}$. Uno (1958). A case of peritonitis chron. fibrosa incapsulata mistaken for the portal thrombosis. (in Japanese) Yokohama Igaku, $9: 338$ 342.

29) Tiese nha u se n, K. (1925). Ein weiterer Fall von Zuckergussdarm (Serositis chron. adhaesiva jejuni-ilei). Zentb. f. Chir., 1925, Nr. 19, S. 1038.

30) To o l e, H. (1929). Beitrag zur Aetiologie und Behandlung des Zuckergussdarmes. Zentb. f. Chir., 1929, Nr. 44, S. 2810. (Deut. Z. f. Chir., 213 : 44, 1928.)

31) W a k a n a, S. (1941). A case of peritonitis chron. fibrosa incapsulata combined with the situs inversus. (in Japanese) Jap. J. Surg., $42:$ 733-744.

32) Y a m a moto, J. (1939). A case of peritonitis chron. fibrosa incapsulata, with a supplement to its aetiology. (in Japanese) Grenzgebiet, $13: 1248-1254$.

\section{Explanation of Plate I}

Fig. 7. Anterior view of the peritoneal sac, when the abdominal wall is cut open.

Fig. 8. The sac is pushed toward right by the finger. The sac has no connection with the omentum majus.

Fig. 9. The sac is cut open longitudinally on both sides of the ascending colon.

Fig. 10. The whole anterior wall of the sac is cut open and the windings of the small intestine are seen. 
Plate I
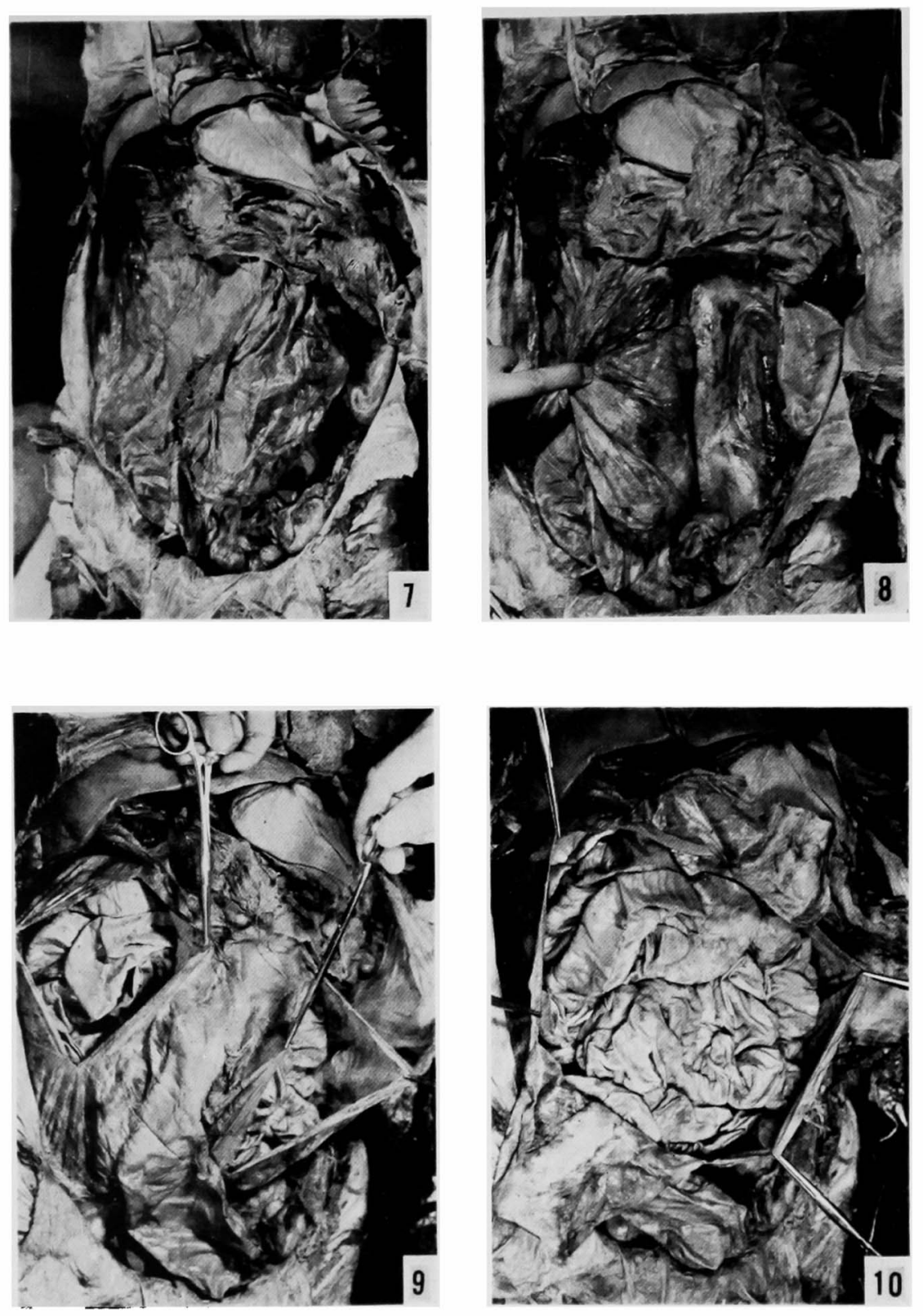

H. Hosokawa and Y. Nakajima 


\section{Explanation of Plate II}

Fig. 11. The small intestine is pushed downward. The duodeno-jejunal junction is seen on the left.

Fig. 12. The intestinal loop is pushed to right of the cadaver, so as to show the radix mesenterii, which attaches to the posterior abdominal wall longitudinally on the right side of the vertebral column.

Fig. 13. The foramen of the ileo-caecal junction seen from inside the sac. A loop of small intestine is seen to pass through the foramen.

Fig. 14. The foramen seen from below and outside the sac. The appendix vermiformis is seen partially embedded in the peritoneal covering. 
Plate II
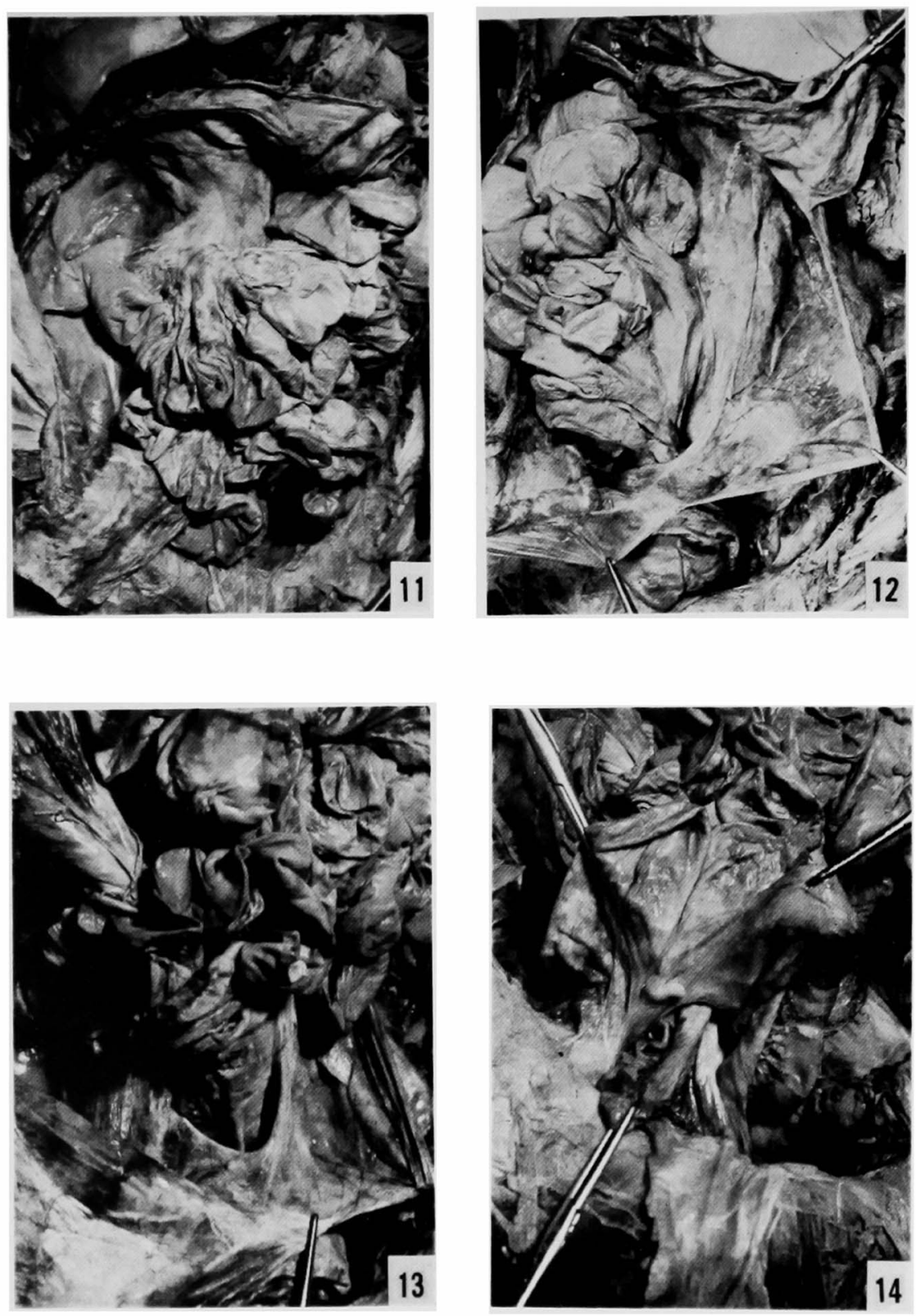

H. Hosokawa and Y. Nakajima 